\title{
Advances in Diagnostic and Molecular Pathology
}

\author{
Semir Vranićc ${ }^{1,2}$, Ivan Damjanov ${ }^{3}$ \\ ${ }^{1}$ College of Medicine, QU Health, Qatar University, Doha, Qatar, ${ }^{2}$ Biomedical and Pharmaceutical Research Unit, QU Health, \\ Qatar University, Doha, Qatar, ${ }^{3}$ The University of Kansas School of Medicine, Kansas City, Kanas, United States
}

Correspondence: semir.vranic@gmail.com or svranic@qu.edu.qa and idamjano@kumc.edu; Tel.: + 97444037873 ; Fax.: + 974 44032250

Received: 19 March 2021; Accepted: 20 March 2021

Key Words: Pathology - Diagnostics - Molecular Pathology.

Early studies of pathogenesis and classification of human diseases in the late $19^{\text {th }}$ and the first half of the $20^{\text {th }}$ century were primarily based on microscopic examination of hematoxylin and eosinstained light microscopy slides and autopsy studies. The introduction of immunohistochemistry in the mid-70 enabled further identification and more precise classification of human diseases, particularly cancer diagnostics (1). In the past three decades, advances in molecular biology, genetics, and genomics have dramatically changed the practice of diagnostic pathology worldwide (2). As never before, pathologists are at the crossroads between the traditionally 'visible' morphologic approach and an 'invisible' molecular science.

Given that molecular diagnostics has become widely utilized in histopathologic diagnosis and clinical decision-making, the policymakers had to reframe the process of accreditation and re-accreditation of the modern pathologists in context to the rapid changes taking place in this diagnostic discipline. This has already been the case in most developed countries, while in the developing world, this integration has yet to be fully implemented. In particular, the concept of "precision medicine" (including pathology) is rapidly evolving and becoming a cornerstone of modern cancer management (reviewed here by Vranic and
Gatalica and nicely illustrated by a comprehensive case study of Trivedi et al.) (2, 3). Equally important in the digital era are pathology informatics, as nicely reviewed in the paper of Kim et al. (4). Their experience with pathology informatics training and education during the challenging COVID-19 pandemic at the Memorial Sloan Kettering Cancer Center is a good example of how informatics can be useful in solving current worldwide health problems (4).

This special issue of Acta Medica Academica highlights the advances in the understanding, diagnostics, and classification of various human cancers. You will note that the authors, all experts in their respective fields, approached their papers on various cancers in different ways. However, all the papers will clearly reflect the authors' strong appreciation for the progress made in the recent decades in diagnostic and molecular pathology. This progress has undoubtedly laid a firm foundation for the future of diagnostic and molecular pathology.

In each of the following reviews $(\mathrm{N}=12)$, original, case studies, and images in clinical medicine $(\mathrm{N}=4)$, the authors provide recent advances and perspectives that are only achieved by their active involvement in the forwarding paths of progress in diagnostic and molecular pathology. Each of the accepted manuscripts was selected based on their 
professional and academic standing and contributions to diagnostic and molecular pathology.

We are happy for contributions from different countries (United States, United Kingdom, Croatia, Slovenia, Serbia, Qatar), including Bosnia and Herzegovina. All of the reviews contain in-depth and up to date information on testicular cancer (5), prostate cancer (6), endocervical adenocarcinoma (7), bladder cancer (8), pleural mesothelioma (9), adult brain tumors (10), and Spitz melanocytic lesions (11). In her review, Dr. Provenzano discussed the most recent advances and challenges in the assessment of breast cancer specimens following neoadjuvant chemotherapy (12). Two hematopathology reviews summarized the advances in this rapidly evolving branch of pathology (13, 14); the first by Perry et al. summed up the critical aspects of diagnosis of the classical Hodgkin lymphoma (13), and the second one by KurtovićKozarić et al. explored the recent advances and challenges in the diagnosis of myeloid neoplasms. It is worth noticing that the latter paper's emphasis is on the improved hematopathology diagnostics in Bosnia and Herzegovina, showing that the advances in pathology have no borders (14). The study of Gargano et al. confirmed the clinical utility of ancillary molecular assays in cytologically indeterminate thyroid nodules (15), while Tomita comparatively analyzed the distribution of blood and lymphatic vessels in normal human vs. rhesus monkey samples (using immunohistochemistry on formalin-fixed and frozen section specimens) (16). Two studies (Trivedi et al.) (3) and Ibisevic et al. (17) illustrated the importance of the multidisciplinary approach and the role of (molecular) tumor boards in cancer management.

As the guest editors of this special issue of Acta Medica Academica, we would like to thank all the contributors for entrusting their work to this journal. These days, in the midst of the COVID-19 epidemic, we are very proud that we managed to collate AMA's special issue that contains scientific contributions from many parts of the world. Like the former present of US Franklin Roosevelt in his last address to the nation, we would like to quote Thomas Jefferson from more than 200 years ago: "The brotherly spirit of science unites into one family all its votaries of whatever grade, and however, widely dispersed throughout the different quarters of the globe." To this quote, Roosevelt added "If civilization is to survive, we must cultivate the science of human relationships" (18) overcoming national, ethnic, and political differences to forge a better world.

At the end, we would like to express our deepest gratitude to all of the reviewers and the editorial staff of AMA, particularly to Mrs. Nerma Tanović. They have altruistically taken so much of their time to improve others' work and served as guardians of the medical literature. Our thanks also to Professor and Academician Husref Tahirović, who invited us to edit this special issue of AMA. We salute you all!

We hope that the readers of Acta Medica Academica will enjoy reading these articles as much as we have!

Conflict of Interest: The authors declare that they have no conflict of interest.

\section{References}

1. Gatalica Z, Feldman R, Vranić S, Spetzler D. Immunohistochemistry-enabled Precision Medicine. Cancer Treat Res. 2019;178:111-35.

2. Vranic S, Gatalica Z. The Role of Pathology in the Era of Personalized (Precision) Medicine: A Brief Review. Acta Med Acad. 2021;50(1):47-57.

3. Trivedi H, Hamdani O, Thomas B, Richard J, Shah K, Raskina K, et al. Patient with Lobular Carcinoma of the Breast and Activating AKT1 E17K Variant. Acta Med Acad. 2021;50(1):209-17.

4. Kim D, Hanna MG, Vanderbilt C, Sirintrapun SJ. Pathology Informatics Education during the COVID-19 Pandemic at Memorial Sloan Kettering Cancer Center (MSKCC). Acta Med Acad. 2021;50(1):136-42.

5. Damjanov I. Testicular Germ Cell Tumors: Serological and Immunohistochemical Diagnosis. Acta Med Acad. 2021;50(1):58-70.

6. Krušlin B, Škara L, Vodopić T, Vrhovec B, Murgić J, Štimac $\mathrm{G}$, et al. Genetics of Prostate Carcinoma. Acta Med Acad. 2021;50(1):71-87.

7. Cimic A, Liu-Jarin X. Updated Review on Pathology of Endocervical Adenocarcinoma with Emphasis on Clinically Relevant Findings. Acta Med Acad. 2021;50(1):12635. 
8. Ulamec M, Murgić J, Novosel L, Tomić M, Terlević R, Tomašković I, et al. New insights into the diagnosis, molecular taxonomy, and treatment of bladder cancer. Acta Med Acad. 2021;50(1):143-56.

9. Savic I, Myers J. Update on diagnosing and reporting malignant pleural mesothelioma. Acta Med Acad. 2021;50(1):197-208

10. Brandner S. Molecular Diagnostics of Adult Gliomas in Neuropathological Practice. Acta Med Acad. 2021;50(1):2946.

11. Šekoranja D, Pižem J, Luzar B. An update on molecular genetic aberrations in Spitz melanocytic proliferations: Correlation with morphological features and biological behavior. Acta Med Acad. 2021;50(1):157-74.

12. Provenzano E. Neoadjuvant Chemotherapy for Breast Cancer: Moving Beyond Pathological Complete Response in the Molecular Age. Acta Med Acad. 2021;50(1):88-109.

13. Perry AM, Smith LB, Bagg A. Classic Hodgkin Lymphoma - Old Disease, New Directions: An Update on Pathology, Molecular Features and Biological Prognostic Markers. Acta Med Acad. 2021;50(1):110-25.

14. Kurtovic-Kozaric A, Islamagic E, Asic A, MehinovicCavcic L, Besic L, Sahinbegovic H, et al. A review of mo- lecular and genetic diagnostics of myeloid malignancies with emphasis on diagnostics in Bosnia and Herzegovina. Acta Med Acad. 2021;50(1):175-96.

15. Gargano SM, Badjatia N, Nikolaus Y, Peiper SC, Wang $\mathrm{Z}$-X. Characterization and clinical significance of EIF1AX mutations and co-mutations in cytologically indeterminate thyroid nodules: A 5-year retrospective analysis. Acta Med Acad. 2021;50(1):4-12.

16. Tomita T. Immunohistochemical Staining for Lymphatic and Blood Vessels in Normal Tissues: Comparison between Routinely Paraffin-embedded Tissues and Frozen Sections. Acta Med Acad. 2021;50(1):13-28.

17. Ibisevic N, Bajrovic J, Saranovic E, Spiritovic D, Skenderi F, Vranic S. A Giant, Complex Fibroepithelial Tumor of the Breast: Borderline Phyllodes Tumor Combined with Tubular Adenoma - a Rare Clinical Presentation of a Fibroepithelial Tumor of the Breast. Acta Med Acad. 2021;50(1):218-20.

18. Newsday [homepage on the Internet], [cited $2021 \mathrm{Feb}$ 27]. Available from: https://www.newsday.com/opinion/ coronavirus/fdr-speech-coronavirus-pandemic-crisismanagement-trump-covid-19-1.43836010. 